\title{
Serological and Molecular Detection of Japanese Encephalitis in Naturally Infected Pigs of Punjab, India
}

\author{
K.M. Lokesh ${ }^{1}$, J.P.S. Gill ${ }^{2}$, N.K. Singh ${ }^{3}$, R. Verma ${ }^{3}$, \\ Simranpreet Kaur ${ }^{4}$ and R.S. Aulakh ${ }^{4}$
}

1 "School of Public Health and Zoonoses" Guru Angad Dev Veterinary and Animal Sciences University (GADVASU), Ludhiana, Punjab, India

${ }^{2}$ GADVASU, Ludhiana, Punjab, India

${ }^{3}$ School of Animal Biotechnology, GADVASU, Ludhiana, India

${ }^{4}$ SPHZ, GADVASU, Ludhiana, Punjab, India

*Corresponding author

\begin{tabular}{|l|}
\hline K e y w o r d s \\
Japanese \\
encephalitis, \\
ELISA, RT-PCR, \\
Pigs and Punjab \\
\hline Article Info \\
\hline $\begin{array}{l}\text { Accepted: } \\
\text { 24 February } 2018 \\
\text { Available Online: } \\
\text { 10 March } 2018\end{array}$ \\
\hline
\end{tabular}

\section{Introduction}

Japanese encephalitis (JE) is a common mosquito borne flaviviral encephalitis prevalent worldwide, mostly in eastern and southern Asia. Japanese Encephalitis Virus
(JEV) has gained a zoonotic importance due to its epidemic potential and high fatality rate in humans and animals (Tiwari et al., 2012). Pigmosquito-pig and bird-mosquito-bird are two basic transmission cycles persist in nature. Swine plays important role as an amplifying 
host in disease transmission, although clinically it is often remain under reported in pig population. It is enzootic in India and most commonly associated with rice growing fields in the rural areas where water logging and irrigation system provides healthy environment for mosquito breeding. The epidemiological pattern and virus activity is greatly influenced by climate, geography and immune status of the host population (Gubler, 1998). Despite of prevalent environmental and ecological factors along with host pig population and mosquito vectors for the spread of JEV in Punjab, number of reported human cases is very scanty as compared to the reported cases in other parts of north India.

Disease history, virus exposure and clinical features cannot help to diagnose JE specifically; hence diagnosis must rely on laboratory confirmation. Molecular and immunological diagnostics are reliable for identification of JEV. In the light of above mentioned facts and considering the limited availability of literature on prevalence of Japanese encephalitis in pigs of Punjab, the present study was conducted to map the presence of JEV by detecting IgG antibodies to JEV with commercial ELISA kit and also the viral nucleic acid (RNA) by RT-PCR in naturally infected pigs of Punjab.

\section{Materials and Methods}

\section{Selection of animals and study area}

Presence of swine population in peridomestic area of Punjab greatly influences the risk to human population. The pigs are the important risk factor for human infection because of their role as an amplifying host of virus. Further, considering Punjab being one of the largest growers of rice in India, the rice fields and stagnant water due to irrigation into the fields, serve as the primary breeding grounds for some of the mosquitoes spreading JEV.
Also, previous work conducted in and around the adjoining states of Punjab has shown the prevalence of mosquito vectors needed for transmitting JEV. Therefore, in the present study pigs were screened for JEV infection considering their role in perpetuation of virus in nature.

\section{Sample collection}

A total of 364 sera and blood samples of pigs from Chandigarh (206), Ludhiana (108) and Jalandhar (50) cities were collected from pig slaughter houses and local retail pork shops located in the aforementioned places of Punjab. The blood samples from the same animal were collected in both EDTA and EDTA free vials for conducting seroprevalence and molecular studies. The samples were transported to the laboratory on ice packs under cold condition. At laboratory the serum was separated by centrifugation at $5000 \mathrm{rpm}$ for $10 \mathrm{~min}$ and stored at $20^{\circ} \mathrm{C}$ until used. Blood collected in EDTA vials were immediately processed for RNA isolation.

Seroprevalence of JEV in pigs using commercial Enzyme linked immunoassay kit

For seroprevalence study an indirect, ELISA was performed using commercially available porcine JE IgG antibody detection kit (Krishgen Biosystem, USA) as per the manufacturer's protocol.

\section{Molecular detection of $\mathrm{JEV}$ in pig blood samples by RT-PCR}

The ssRNA was extracted with TRIzol-LS reagent (Invitrogen, USA) as per the manufacturer's protocol and was immediately processed for synthesis of cDNA. Synthesized cDNA was subjected to the PCR amplification in a $2 \mu \mathrm{l}$ reaction volume containing $2.5 \mu \mathrm{l}$ of 10X PCR buffer (without $\mathrm{MgCl}_{2}$ ), $1.5 \mu \mathrm{l}$ 
$\mathrm{MgCl}_{2}, 2.5 \mu \mathrm{l}$ of $2 \mathrm{mM}$ dNTPs, $1 \mu \mathrm{l}$ each of diagnostic envelope primers ( $10 \mathrm{pmol} / \mu \mathrm{l}), 5 \mu \mathrm{l}$ Template cDNA, $0.3 \mu \mathrm{T}$ Taq DNA Polymerase $(5 \mathrm{U} / \mu \mathrm{l})$ and $\mathrm{NFW}$ up to $25 \mu \mathrm{l}$. Amplification was performed in a thermocycler (AB Applied Biosystem). The results obtained by the diagnostic primers were cross confirmed by screening all the positive samples by other two sets of primers targeting NSI and Env genes (Table 1).

\section{Statistical analysis}

Chi-squared test was employed to analyze differences in JEV prevalence between three districts. A $p$-value less than 0.05 were considered to be statistically significant.

\section{Results and Discussion}

Seroprevalence of JEV in pigs using commercial Enzyme linked immunoassay kit

The results of the present study revealed that out 364 sera samples from Chandiagrh (206), Ludhiana (108) and Jalandhar (50), anti JE IgG antibodies were detected in 48/206, $10 / 108$ and 5/50 pig sera samples from Chandigarh, Ludhiana and Jalandhar, respectively. Therefore, an overall seroprevalence of $17.3 \%(63 / 364)$ was reported in pigs from Punjab wherein, 23.30 $\%$ (95\% CI 29.7-18\%), $9.25 \%$ (95\% CI $15-$ $5.6 \%)$ and $10 \%$ (95\% CI 19.1-6.6\%) seroprevalence was recorded in Chandigarh, Jalandhar and Ludhiana districts of Punjab, respectively. When analyzed the place wise sero-prevalence the higher prevalence of IgG antibodies for JE was observed in sera samples obtained from pigs slaughtered at Chandigarh slaughter house followed by pigs from Ludhiana and least prevalence was noted in Jalandhar (Table 2). The sero-prevalence of JEV in pigs from three districts of Punjab was found to be statistically significant at $5 \%$ level of significance $(\mathrm{p}=0.002575$, Chi-squared $=$ 11.9238). The obtained overall seroprevalence of $17.30 \%(63 / 364)$ in Punjab state in the present study was lower than that reported in Uttar Pradesh (27.88\%) and Tamil Nadu (65.21\%) (Rawat, 2013) since, these areas are endemic for JE so, seropositivity can go upto $100 \%$ in the pig population (Acha and Szyfrez, 2003). The reported sero-prevalence of $23.30 \%$ in Chandigarh is in accordance with the studies from Bareilly and Tamil Nadu wherein a sero-prevalence of $20.83 \%$ and $26.4 \%$ was recorded (Kolhe, 2008; Kumanan et al., 2002). Sstudies from other parts of India reported variable JE sero-prevalence in pigs as $18 \%$ from Haryana and $30.3 \%$ by $\mathrm{HI} ; 12.5 \%$ by CFT from Chandigarh (Nagaleelavathi et al., 2008; Ratho et al., 1999). Higher prevalence was reported in pigs from the rice cultivating districts of Kurukshetra (43.8\%), Ambala (10.7\%), Karnal (7.7\%) and Yamunanagar $(7.1 \%)$ in comparison to that in the non-rice growing Hisar district (3.7\%) (Nagaleelavathi et al., 2008). A serosurveillance of JE in relation to temporal and spatial distribution in swine population of endemic areas revealed maximum seroprevalence from Tripura (61.53\%) followed by Uttar Pradesh (29.33\%) and Punjab (28.57\%) (Dhanze et al., 2014). Kolhe et al., (2015) recorded $28.89 \%$ overall prevalence of JE by IgG-ELISA with highest from North East region of India (35.22\%), followed by Chandigarh (31.03\%), Goa (29.00\%), Deonar slaughter house, Mumbai (25.89\%), Bareilly (20.83\%) and IVRI Pig farm $(20.00 \%)$ for IgG antibodies.

The reason for the high positivity obtained in the present study could be attributed to the time of sample collection, difference in the geographical area and differences in the socioeconomic status of the people, standard of living, animal and vector populations, and favourable environmental conditions prevailing in the regions. 
Table.1 Oligonucleotide primer pairs

\begin{tabular}{|c|c|}
\hline Sl. No & Gene \\
\hline 1. & $\begin{array}{c}\text { Diagnostic } \\
\text { Env gene }\end{array}$ \\
\hline 2. & $\begin{array}{c}\text { Envelope } \\
\text { gene }\end{array}$ \\
\hline 3. & NS1 gene \\
\hline
\end{tabular}

Primer Sequence (5'-3')

JEDR-GCTCCTTCGACAACCCTCAA

JEDF-ACGATGTAGGAGTCCCCGAA

JEEF-GAGGTCTAGAATGTTCAACTGTCTGGGAATGGGC

JEER-TGGTGCTCGAGAGCATGCACATTGGTCGCTAAG

JENF-AGGAGGTCTAGAATGGACACTGGATGTGCCATTG

JENR-TGGTGCTCGAGTAGCACCACATACCTCGC

Table.2 The sero-prevalence of JEV antibodies using an Indirect- ELISA in slaughtered pigs in Punjab, India

\begin{tabular}{|c|c|c|c|c|c|}
\hline Species & Place & $\begin{array}{l}\text { No. of } \\
\text { samples } \\
\text { collected }\end{array}$ & $\begin{array}{l}\text { No. of } \\
\text { positive } \\
\text { samples }\end{array}$ & $\begin{array}{c}\text { No. of } \\
\text { negative } \\
\text { samples }\end{array}$ & $\begin{array}{c}\text { Sero-prevalence } \\
\text { (95\% Confidence Interval) }\end{array}$ \\
\hline \multirow[t]{3}{*}{ Pig } & Chandigarh & 206 & 48 & 158 & $23.30 \%$ (95\% CI $29.7-18 \%)$ \\
\hline & Ludhiana & 108 & 10 & 98 & $9.25 \%$ (95\% CI $15-5.6 \%)$ \\
\hline & Jalandhar & 50 & 5 & 45 & $10 \%$ (95\% CI 19.1-6.6\%) \\
\hline \multicolumn{2}{|l|}{ Total } & 364 & 63 & & $17.30 \%$ \\
\hline
\end{tabular}

Table.3 Molecular prevalence of Japanese Encephalitis virus in pigs

\begin{tabular}{|c|c|c|c|c|}
$\begin{array}{c}\text { Place of } \\
\text { collection }\end{array}$ & $\begin{array}{c}\text { Seropositive } \\
\text { samples }\end{array}$ & $\begin{array}{c}\text { RT-PCR } \\
\text { positive } \\
\text { samples }\end{array}$ & $\begin{array}{c}\text { Molecular positivity } \\
\text { in seropositive } \\
\text { samples }\end{array}$ & $\begin{array}{c}\text { Overall molecular } \\
\text { prevalence from } \\
\text { Punjab }\end{array}$ \\
\hline Chandiagarh & 48 & 17 & & \\
\hline Ludhiana & 10 & 3 & $31.74 \%(20 / 63)$ & $5.49 \%(20 / 364)$ \\
\hline Jalandhar & 5 & 0 & & \\
\hline Total & $\mathbf{6 3}$ & $\mathbf{2 0}$ & & \\
\hline
\end{tabular}

Fig.1 RT-PCR showing amplification of diagnostic Env gene of JEV in seropositive samples

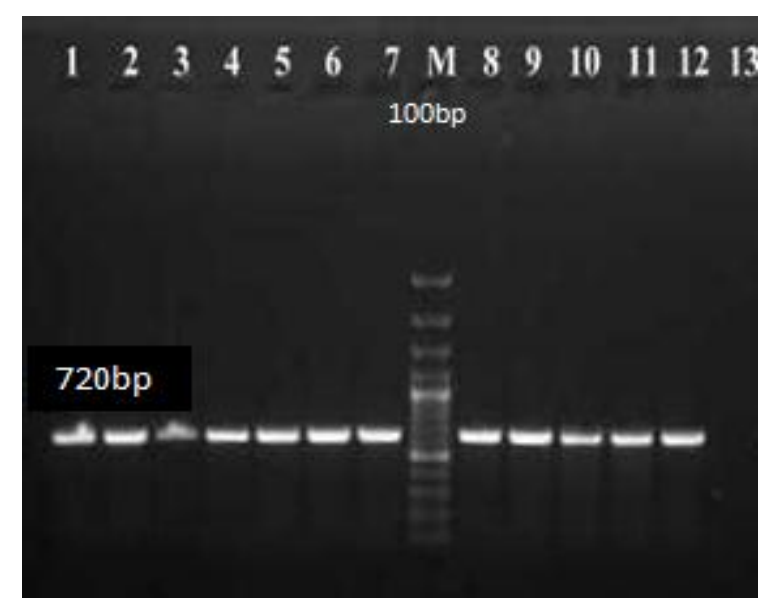


Fig.2 RT-PCR showing amplification of NS1 and Env gene of JEV in seropositive samples

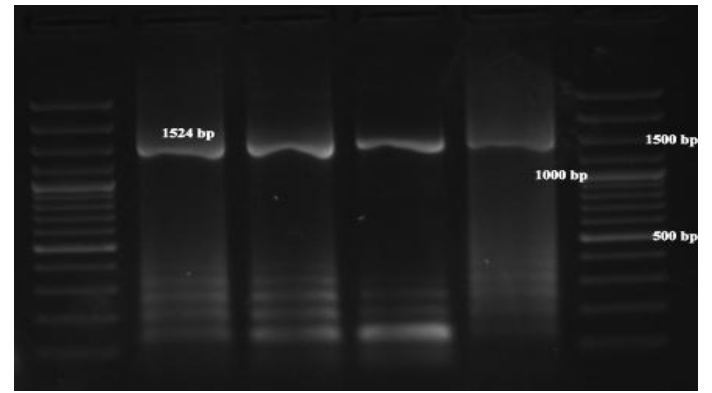

The regions of Punjab from which the sera samples were collected are well known endemic regions for JEV persistence. In the present study sero-positivity in swine from Chandigarh slaughter house was recorded to be high which could be attributed to the fact that pigs brought for slaughter there were mostly from the adjoining states of India which are JE endemic regions.

\section{Molecular detection of JEV in blood samples obtained from pigs by RT-PCR}

The results of RT-PCR revealed that 20 out of 63 seropositive blood samples with amplified 720 bp products of JEV envelope gene with diagnostic primers (Fig. 1). 17/48 seropositive samples were from Chandigarh, 3/10 samples were from Ludhiana and none of the five seropositive samples from Jalandhar were positive for JEV nucleic acid.

All the sero-negative blood samples turned out to be negative in molecular assay for JEV. Therefore, the RT-PCR based molecular prevalence of $31.74 \%$ was reported in JEV seropositive pigs of Punjab. Maximum prevalence of $35.41 \%$ (17/48), followed by 30 $\%(3 / 10)$ and nil was observed in pigs from Chandigarh, Ludhiana and Jalandhar, respectively. Overall molecular prevalence of $5.49 \%$ (20/364) was recorded in pigs of Punjab (Table 3 ). The results obtained by the diagnostic primers were cross checked by screening all the positive samples by other sets of primers targeting NSI and Env gene which amplified the expected band size of approximately 1524 bp

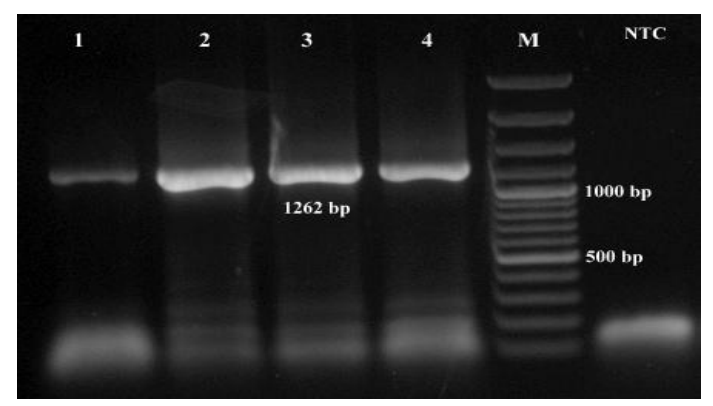

and 1262 bp, respectively (Fig. 2). The chi square test was not found significant for molecular prevalence between Chandigarh and Ludhiana districts of Punjab $(\mathrm{p}=0.945169$, Chisquare $=0.0047)$. The present study revealed an overall lower molecular prevalence of JEV in pigs of Punjab.

Although PCR based assays for diagnosis of JE in humans have been developed in India (Parida et al., 2006b; Santhosh et al., 2007), but this theory remained neglected in swine population. A study at IVRI reported $4.4 \%$ and $17.77 \%$ field swine blood samples to be positive for JEV by RT-PCR and RT-LAMP, respectively (Dhanze, 2014). The results of present study confirm existence of Japanese encephalitis virus in pigs of Punjab.

The infection risk in pigs has remarkable importance regarding the transmission of JEV infection to humans. Therefore, the potential risk of the disease transmission by mosquito bites from pigs should be considered as a public health problem.

\section{Acknowledgments}

The authors wish to thank Guru Angad Dev Veterinary and Animal Sciences University, Ludhiana for financially supporting this study.

\section{Conflict of Interest}

Authors have no conflict of interest related to this study. 


\section{References}

Acha, P. N., and Szyferz, B. 2003. Japanese encephalitis. In. Zoonoses and communicable diseases common to man and animals. Vol. III, Chlamydioses, Rickettsioses and Viroses. 3rd Edn. Scientific and technical publication no. 580. PAHO, NY, Washington DC, USA. pp. 172-176.

Dhanze, H. 2014. 'Development of rapid on-site diagnostic assays for Japanese encephalitis in swine'. Ph.D. Thesis, Deemed University Indian Veterinary Research Institute Izatnagar, India.

Dhanze, H., Bhilegaonkar, K. N., Rawat, S., Chethan, H. B., Kerketta, P., Dudhe, N. and Kumar, A. 2014. Seasonal seroprevalence of Japanese encephalitis in swine using indirect IGg ELISA. Journal of Veterinary Public Health, 12 (2): 15-18

Gubler, D. J. 1998. Dengue and dengue hemorrhagic fever. Journal of Clinical Microbiology, 11: 480-496.

Kolhe, R. P. 2008. 'Development and evaluation of ELISA and RT-PCR for diagnosis of Japanese encephalitis'. Ph.D. Thesis, Deemed University, IVRI, Izatnagar, India.

Kolhe, R. P., Bhilegaonkar, K. N., Dubal, Z. B., Kaur, S., Samir, D. and Agarwal, R. K. 2015. Indirect ELISA for serosurveillance of Japanese encephalitis in pigs. Indian Journal of Animal Research, 49 (3): 343349.

Kumanan, K., Ramesh, A., Velmurgan, R., Jgannathan, S. and Padmanabhan, V. D. 2002. Seroepidemiology of Japanese encephalitis among animals and birds in Tamil Nadu. Indian Veterinary Journal, 79: 311-315.
Nagaleelavathi, S. P., Gulati, B. R. and Garg, S. R. 2008. Seroprevalence of Japanese encephalitis in pigs in Haryana. Journal of Veterinary Public Health, 6 (1): 37-39.

Parida, M., Santhosh, S. R., Dash, P. K., Tripathi, N. K., Saxena, P. and Ambuj, S. 2006b. Development and evaluation of reverse transcription loop-mediated isothermal amplification assay for rapid and real-time detection of Japanese encephalitis virus. Journal of Clinical Microbiology, 44: 4172-4178.

Ratho, R. K., Sethi, S. and Prasad, S. R. 1999. Prevalence of Japanese encephalitis and West Nile viral infections in pig population in and around Chandigarh. Journal of Communicable Diseases, 31 (2): 113-116.

Rawat, S. 2013. 'Development and evaluation of synthetic peptide and recombinant protein based ELISAs for the serodiagnosis of Japanese encephalitis in swine'. Ph.D. Thesis, Deemed University, IVRI, Izatnagar, India.

Santhosh, S. R., Parida, M. M., Dash, P. K., Pattnaik, B., Pradhan, H. K., Tripathi, N. K., Ambuj, S., Gupta, N., Saxena, P. and Rao, P. V. L. 2007. Development and evaluation of SYBR Green I-based onestep real-time RT-PCR assay for detection and quantitation of Japanese encephalitis virus. Journal of Virological Methods, 143: 73-80.

Tiwari S., Singh, R. K., Tiwari, R. and Dhole, T. N. 2012. Japanese encephalitis: a review of the Indian perspective. Brazilian Journal of Infectious Diseases, 16 (6): 564-573.

\section{How to cite this article:}

Lokesh, K.M., J.P.S. Gill, N.K. Singh, R. Verma, Simranpreet Kaur and Aulakh, R.S. 2018. Serological and Molecular Detection of Japanese Encephalitis in Naturally Infected Pigs of Punjab, India. Int.J.Curr.Microbiol.App.Sci. 7(03): 2822-2827. doi: https://doi.org/10.20546/ijcmas.2018.703.324 